\title{
PICK1 Regulates Incorporation of Calcium-Permeable AMPA Receptors during Cortical Synaptic Strengthening
}

\author{
Roger L. Clem, ${ }^{1,2}$ Victor Anggono, ${ }^{1,2}$ and Richard L. Huganir ${ }^{1,2}$ \\ ${ }^{1}$ Department of Neuroscience and ${ }^{2}$ Howard Hughes Medical Institute, Johns Hopkins University School of Medicine, Baltimore, Maryland 21205
}

While AMPA-type glutamate receptors (AMPARs) found at principal neuron excitatory synapses typically contain the GluR2 subunit, several forms of behavioral experience have been linked to the de novo synaptic insertion of calcium-permeable (CP) AMPARs, defined by their lack of GluR2. In particular, whisker experience drives synaptic potentiation as well as the incorporation of CP-AMPARs in the neocortex. Previous studies implicate PICK1 (protein interacting with C kinase-1) in activity-dependent internalization of GluR2, suggesting one potential mechanism leading to the subsequent accumulation of synaptic CP-AMPARs and increased synaptic strength. Here we test this hypothesis by using a whisker stimulation paradigm in PICK1 knock-out mice. We demonstrate that PICK1 facilitates the surface expression of CP-AMPARs and is indispensable for their experience-dependent synaptic insertion. However, the failure to incorporate CP-AMPARs in PICK1 knock-outs does not preclude sensory-induced enhancement of synaptic currents. Our results indicate that synaptic strengthening in the early postnatal cortex does not require PICK1 or the addition of GluR2-lacking AMPARs. Instead, PICK1 permits changes in AMPAR subunit composition to occur in conjunction with synaptic potentiation.

\section{Introduction}

A key feature of synaptic strengthening is the subunit-specific trafficking of AMPA-type glutamate receptors (AMPARs), which consist of heterotetrameric assemblies of four closely related proteins known as GluR1-4 (alternatively, GluA1-4 or GluRA-D) (Shepherd and Huganir, 2007). In certain cases, neural activity drives synaptic incorporation of AMPARs that lack the GluR2 subunit [calcium-permeable (CP)-AMPARs] (Liu and Zukin, 2007), a process we refer to as CP-AMPAR plasticity (CARP) (Gardner et al., 2005). Aside from greater calcium permeability (Tempia et al., 1996), CP-AMPARs are characterized by increased conductance (Swanson et al., 1997), accelerated kinetics, and inward rectification (Oh and Derkach, 2005). CP-AMPARs are considered key mediators of synaptic plasticity in many in vivo paradigms, including sensory experience (Clem and Barth, 2006; Goel et al., 2006), drug addiction (Conrad et al., 2008), ischemia (Noh et al., 2005), and epilepsy (Prince et al., 1995).

Although mechanisms that regulate CARP remain largely obscure, studies point to a role for the PDZ ligand located at the extreme C terminus of GluR2 in synaptic removal of GluR2-

Received Dec. 18, 2009; revised March 8, 2010; accepted March 21, 2010.

This work was supported by grants from the National Institutes of Health (NSO36715) and the Howard Hughes Medical Institute (R.L.H.). V.A. was supported by fellowships from the International Human Frontiers Science Program (LT00399/2008-L) and the Australian National Health and Medical Research Council (ID. 477108). R.L.C. was supported by a National Research Service Award from the National Institutes of Health (F32 MH087037-01). We thank Yilin Yu and Monica Coulter for expert technical assistance, and Abigale Lade for critical feedback.

Under a licensing agreement between Millipore Corporation and The Johns Hopkins University, R.L.H. is entitled to a share of royalties received by the University on sales of products described in this article. R.L.H. is a paid consultant to Millipore Corporation. The terms of this arrangement are being managed by The Johns Hopkins University in accordance with its conflict-of-interest policies.

Correspondence should be addressed to Dr. Richard L. Huganir, Department of Neuroscience, Howard Hughes Medical Institute, Johns Hopkins University School of Medicine, 725 North Wolfe Street, Hunterian 1009A, Baltimore, MD 21205. E-mail: rhuganir@jhmi.edu.

DOI:10.1523/JNEUROSCI.6276-09.2010

Copyright $\odot 2010$ the authors $\quad 0270-6474 / 10 / 306360-07 \$ 15.00 / 0$ containing receptors. This motif is bound by the PICK1 (protein interacting with C kinase-1) protein (Xia et al., 1999), which regulates the internalization of GluR2 in long-term depression (LTD) (Xia et al., 2000; Kim et al., 2001; Steinberg et al., 2006; Terashima et al., 2008). The role of PICK1 in CP-AMPAR synaptic localization has been widely examined with dominantnegative peptides that disrupt PICK1-GluR2 binding (Gardner et al., 2005; Liu and Cull-Candy, 2005). For example, treatment with the pep2-EVKI GluR2 C-terminal peptide abolishes rectification of EPSCs (Bellone and Lüscher, 2006; Ho et al., 2007; Bell et al., 2009; Dixon et al., 2009; Park et al., 2009), indicating that PICK1-GluR2 interactions maintain CP-AMPARs at synaptic sites. Although the specificity of these peptides is arguably inadequate, genetic deletion of PICK1 also has effects on CP-AMPAR trafficking, including reduced basal synaptic expression (Ho et al., 2007) as well as impaired activity-dependent replacement of CP-AMPARs (Gardner et al., 2005).

Since the trafficking of CP-AMPARs coincides with increased EPSC amplitudes in many paradigms (Terashima et al., 2004; Bellone and Lüscher, 2006; Clem and Barth, 2006; Goel et al., 2006; Liu et al., 2006; Conrad et al., 2008), an assumption has been that CARP may constitute a mechanism for neural response potentiation. To examine the role of PICK1 in these events, we used a sensory experience paradigm that induces input-specific synaptic strengthening and the appearance of synaptic CPAMPAR currents (Clem and Barth, 2006; Clem et al., 2008). By depriving PICK1 knock-out mice of all but a single row of whiskers (single-row experience), we demonstrate that synaptic $\mathrm{CP}$ AMPAR insertion requires PICK1. However, PICK1 knock-outs display levels of cortical synaptic strengthening during sensory experience similar to those of their wild-type littermates. Biochemical analysis indicates that PICK1 governs basal expression levels of AMPAR subtypes at the neuronal surface. These data 
show that in the early postnatal cortex, PICK1 functions to calibrate the subunit composition of AMPARs that are delivered to strengthened synapses.

\section{Materials and Methods}

Whisker deprivation. PICK1 knock-outs, initially described previously (Gardner et al., 2005), were backcrossed 11 times to C57BL6/J6 and bred as heterozygotes to generate PICK $1+/+$ and PICK1 $1-/-$ subjects. On postnatal day 11 (P11)-P13, mice were lightly anesthetized and the large mystacial whiskers were removed with forceps. A single set of D-row whiskers were left intact, and mice were returned to their home cages for $48 \mathrm{~h}$ until killed.

Slice electrophysiology. Brains were dissected into ice-cold buffer containing the following (in $\mathrm{mm}$ ): 210.3 sucrose, 11 glucose, $2.5 \mathrm{KCl}, 1$ $\mathrm{NaH}_{2} \mathrm{PO}_{4}, 26.2 \mathrm{NaHCO}_{3}, 0.5$ ascorbate, $0.5 \mathrm{CaCl}_{2}, 4 \mathrm{MgCl}_{2}$. Acute slices were obtained at $350 \mu \mathrm{m}$ thickness at a $45^{\circ}$ angle from midline (Finnerty et al., 1999) and transferred to normal artificial CSF (ACSF) composed of the following (in mM): $119 \mathrm{NaCl}, 2.5 \mathrm{KCl}, 1 \mathrm{NaH}_{2} \mathrm{PO}_{4}, 26.2 \mathrm{NaHCO}_{3}, 11$ glucose, $2 \mathrm{CaCl}_{2}$, and $2 \mathrm{MgCl}_{2}$. Following recovery at $35^{\circ} \mathrm{C}$ for $1 \mathrm{~h}$, slices were maintained at $22-25^{\circ} \mathrm{C}$. Whole-cell recordings were performed using borosilicate electrodes ( $3-5 \mathrm{M} \Omega$ ) on slices containing five large barrels, comprising whisker rows A-E (Finnerty et al., 1999). In all cases, the $D$ row was spared. Deprived recordings were obtained from rows $C$ and $\mathrm{E}$ and pooled together for analysis, because of the remaining barrels, these were most comparable in size to the $\mathrm{D}$ barrel. Electrode internal solution contained (in mM) 130 cesium-methanesulfonate, 10 HEPES, 0.5 EGTA, $8 \mathrm{NaCl}, 4 \mathrm{Mg}$-ATP, $1 \mathrm{QX}-314,10 \mathrm{Na}$-phosphocreatine, and $0.4 \mathrm{Na}$-GTP. Monosynaptic responses (3-4 ms latency) were evoked by layer 4 stimulation (50 $\mu$ s pulse) with a concentric bipolar electrode. All experiments were performed in $100 \mu \mathrm{M}$ D,L-APV, except when determining AMPA:NMDA ratios. Picrotoxin $(50-100 \mu \mathrm{M})$ was present during all recordings to block fast GABAergic transmission. To quantify rectification, internal solution was supplemented with $100 \mu \mathrm{M}$ spermine. Asynchronous AMPAR-EPSCs $\left(\mathrm{Sr}^{2+}\right.$-mEPSCs) were evoked in nominally $\mathrm{Ca}^{2+}$-free ACSF containing $3 \mathrm{~mm} \mathrm{Sr}^{2+}$ as previously described (Clem and Barth, 2006). Spontaneous mEPSCs were collected in the presence of $1 \mu \mathrm{M}$ tetrodotoxin. Data were acquired using Multiclamp 700B and pCLAMP 10 (Molecular Devices). AMPA:NMDA ratios were calculated as the ratio of peak current at $-70 \mathrm{mV}$ to the current at $100 \mathrm{~ms}$ after stimulus onset at $+40 \mathrm{mV}$ (since we determined from synaptic responses in D,L-APV that AMPAR currents make a negligible contribution at this interval). Rectification index was calculated as a ratio of slopes of a linear fit of $I-V$ points, in which the index $=$ slope at negative holding potentials $(-70$ to $0 \mathrm{mV})$ divided by the slope at positive holding potentials $(0$ to $+50 \mathrm{mV}$ ). Accordingly, an index of 1 represents perfect linearity, while values $>1$ indicate inward rectification. $\mathrm{Sr}^{2+}$-mEPSCs up to $400 \mathrm{~ms}$ following the stimulus, and excluding the synchronous release event, were detected at $5 \mathrm{pA}$ threshold $(>2 \times$ RMS noise) and analyzed using MiniAnalysis (Synaptosoft). To obtain decay times, mean mEPSCs were fitted with a single exponential. Significance for all group comparisons was assessed by one-way ANOVA followed by a Bonferroni post hoc comparison. Group-pooled $\mathrm{Sr}^{2+}$-mEPSCs were also compared by Kolmogorov-Smirnov test.

Surface biotinylation assays. For surface biotinylation, barrel cortices were dissected out from $350 \mu \mathrm{m}$ acute coronal brain slices following $1 \mathrm{~h}$ recovery at $35^{\circ} \mathrm{C}$. Barrel cortical slices were then transferred to ice-cold ACSF for $10 \mathrm{~min}$ followed by incubation with $1 \mathrm{mg} / \mathrm{ml}$ Sulfo-NHS-SSBiotin (Pierce) for $20 \mathrm{~min}$ on ice. Free biotin was quenched by washing slices with ice-cold TBS (in mu, 50 Tris- $\mathrm{HCl}, 150 \mathrm{NaCl}, \mathrm{pH}$ 7.4). Slices were lysed in RIPA buffer and incubated with NeutrAvidin beads (Pierce) at $4^{\circ} \mathrm{C}$ for $3 \mathrm{~h}$. Beads were washed three times in RIPA buffer and eluted with $2 \times$ SDS sample buffer, followed by SDS gel electrophoresis and Western blotting analyses. Specific antibodies against GluR1 (4.9D) and PICK1 (JH2906) were generated in-house. Monoclonal antibody against GluR2 and $\alpha$-tubulin were purchased from Millipore and Sigma, respectively. Quantitative analyses of Western blots were performed by determining the intensity of each band on the developed films with ImageJ software. Values for surface and total AMPAR subunit levels were normalized to total protein load determined by $\alpha$-tubulin blot following background correction. The surface/total ratio was simply a division of the two values. Significance was assessed by two-tailed $t$ test comparing surface/total ratios for PICK1 knock-outs to those of wild-type littermates.

Determination of surface GluR2-lacking AMPAR levels. Cortices were dissected out from $350 \mu \mathrm{m}$ acute coronal brain slices following $1 \mathrm{~h}$ recovery at $35^{\circ} \mathrm{C}$. Cortical slices were then transferred to ice-cold ACSF for $10 \mathrm{~min}$ followed by incubation with $1 \mathrm{mg} / \mathrm{ml}$ Sulfo-NHS-SS-Biotin (Pierce) for $20 \mathrm{~min}$ on ice. Free biotin was quenched by washing slices with ice-cold TBS (in $\mathrm{mm}, 50$ Tris- $\mathrm{HCl}, 150 \mathrm{NaCl}, \mathrm{pH}$ 7.4). Slices were lysed in RIPA buffer and the total protein concentration was determined by BCA assay. One hundred micrograms of cortical lysate were incubated overnight with $10 \mu \mathrm{g}$ of anti-GluR2 antibodies (JH3724). The unbound fraction was subjected to another round of immunoprecipitation with the same antibodies for another $3 \mathrm{~h}$ at $4^{\circ} \mathrm{C}$. Two rounds of immunoprecipitation effectively pulled down $>95 \%$ of GluR2. After the second immunoprecipitation, the unbound fraction was incubated with NeutrAvidin beads (Pierce) at $4^{\circ} \mathrm{C}$ for $3 \mathrm{~h}$. Beads were washed three times in RIPA buffer and eluted with $2 \times$ SDS sample buffer, followed by SDS gel electrophoresis and Western blotting analyses. Quantitative analyses of Western blots were performed by determining the intensity of each band on the developed films with ImageJ software. The percentage of total and surface AMPAR subunits remaining in the unbound fraction was calculated by normalizing band intensities to the total input values. Significance was assessed by comparing these final normalized values for PICK1 knock-outs with those of wild-type littermates by two-tailed $t$ test.

\section{Results}

The cortical whisker representation of the rodent is an excellent system for examining sensory-induced plasticity (Feldman and Brecht, 2005). In particular, partial whisker deprivation triggers competitive plasticity resulting in greater excitation of cortical neurons in response to spared whisker deflection (Glazewski and Fox, 1996; Glazewski et al., 2007). A brief period of single-whisker experience increases the efficacy of AMPAR-transmission in the cortical layer $4-2 / 3$ pathway and results in the appearance of CP-AMPARs at these same inputs (Clem and Barth, 2006; Clem et al., 2008).

To target sensory-stimulated neurons with greater ease, we adapted the single-whisker protocol to produce a complete row of spared whiskers. Prior studies in which multiple whisker rows have been spared have demonstrated long-term potentiation (LTP)-like enhancements in transmission within spared whisker columns (Finnerty et al., 1999; Cheetham et al., 2007), suggesting that multiple- versus single-whisker sparing might yield similar plasticity. Accordingly, mice were deprived of all but one unilateral row of whiskers for a period of $48 \mathrm{~h}$ (Fig. $1 \mathrm{~A}$ ).

Taking advantage of an oblique slice preparation containing an ordered arrangement of the large whisker barrels (Finnerty et al., 1999), we then examined layer 4-2/3 excitatory synaptic responses to test for the presence of rectifying CP-AMPARs (Fig. $1 B$ ). In agreement with previous experiments using a single-whisker protocol (Clem and Barth, 2006), we found that single-row experience triggered an increase in rectification of AMPAR-EPSCs at sensory spared layer $4-2 / 3$ inputs in PICK $1+/+$ animals, but not at deprived inputs within the same slice (Fig. $1 B-E$ ). By quantifying the amount of rectification from these $I-V$ plots, we found that significantly more rectification was present in spared synapses from PICK $1+/+$ after single-row experience (Fig. $1 E)$ [rectification index $=$ control $0.98 \pm 0.05(n=$ $7)$, spared $1.41 \pm 0.06(n=9)$, deprived $1.01 \pm 0.03(n=7)]$. In contrast, single-row experience produced no change in AMPAREPSC rectification in PICK1 $-/-$ mice (Fig. $1 D, E$ ) [rectification index $=$ control $1.09 \pm 0.10(n=6)$, spared $1.04 \pm 0.06(n=11)$, 
A

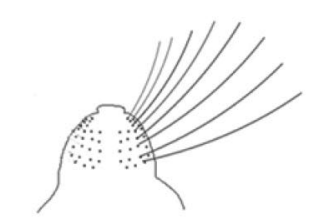

Single Row Experience

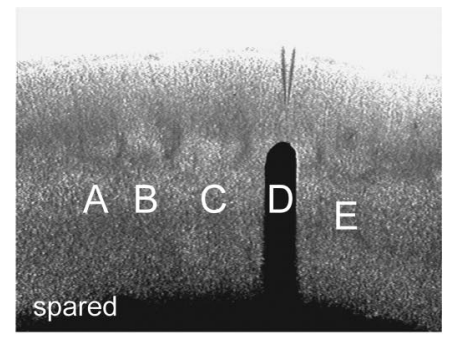

B

PICK1 +/+

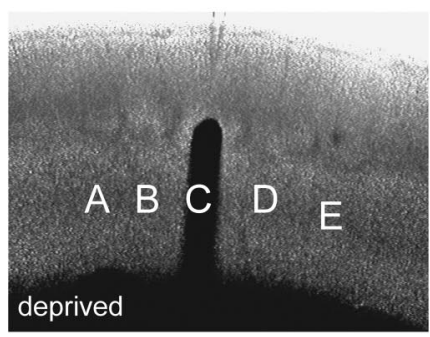

E

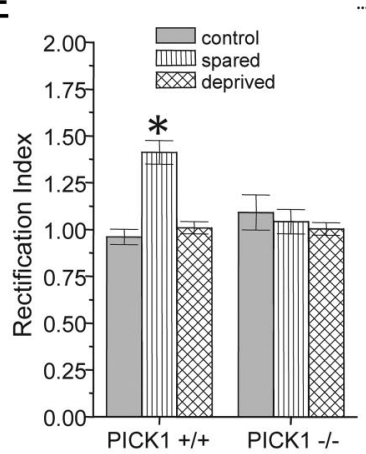

C

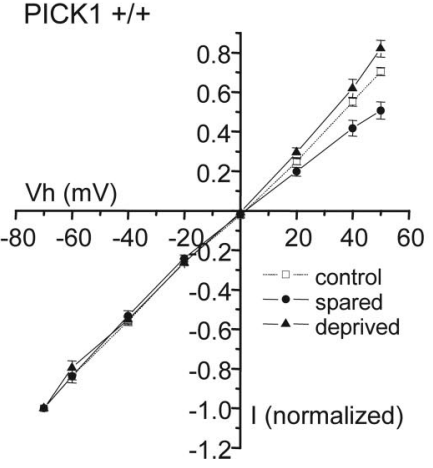

DICK1 $1-$

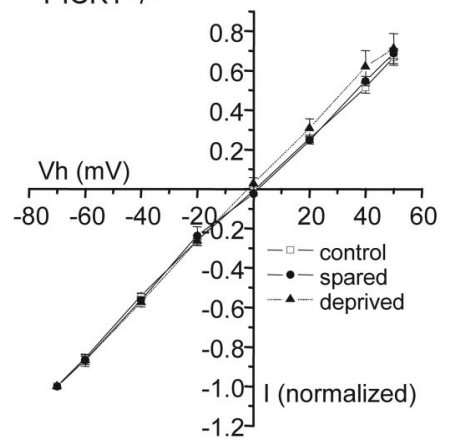

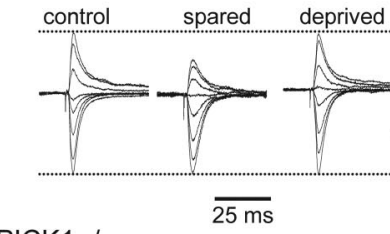

PICK1 -/-

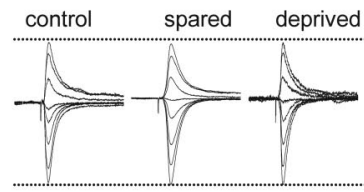

Figure 1. Single-row experience drives PICK1-dependent increase in AMPAR-EPSC rectification at layer 4-2/3 synapses. $\boldsymbol{A}$, Plasticity was induced in PICK1 knock-out mice by single-row experience, which entailed the removal of all but a unilateral D row of whiskers for $48 \mathrm{~h}$. Middle, Right, Stimulus and recording electrode configuration for examination of cortical layer $4-2 / 3$ EPSCS in spared (middle, D column) and deprived (right, C and E columns, pooled) barrel columns after single-row experience. $\boldsymbol{B}, 0$ verlay of layer $4-2 / 3$ AMPAR-EPSCs evoked at the following holding potentials in the presence of internal spermine $(100 \mu \mathrm{M}):-70,-60,-40,-20,0,+20,+40,+50 \mathrm{mV}$. Responses have been normalized to amplitude at $-70 \mathrm{mV}$. C, $D$, Normalized amplitude of AMPAR-EPSCs as a function of holding potential $\left(I-V\right.$ plot) for PICK1 $+/+(\boldsymbol{C})$ and PICK1 $-/-(\boldsymbol{D})$ mice. $\boldsymbol{E}$, Mean rectification index for control and single-row experience mice. ${ }^{*} p<0.001$ by ANOVA followed by Bonferroni post hoc comparison.

deprived $1.00 \pm 0.03(n=6)]$, indicating that PICK1 knock-outs are defective in CARP. The impairment in PICK1-/- mice could not be overcome by lengthening the period of single-row experience to $72 \mathrm{~h}$ [72 h single-row experience, rectification in$\operatorname{dex}=$ spared $1.00 \pm 0.08(n=6)]$, suggesting that the failure to incorporate CP-AMPARs could not be explained by a higher induction threshold.

Having established that PICK1 deletion disrupts CARP, we then asked whether synaptic strengthening was likewise defective in PICK1 - / - mice. A commonly used indicator of prior synaptic strengthening is the ratio of AMPAR-mediated to NMDARmediated current (AMPA:NMDA ratio), in which increases in this ratio reflect augmented AMPAR currents. Surprisingly, recordings performed after single-row experience revealed that AMPA:NMDA ratio was enhanced in both $\mathrm{PICK} 1+/+$ and PICK1 $-/-$ mice within spared barrel columns (Fig. $2 A, B)$ [AMPA:NMDA ratio: $\mathrm{PICK} 1+/+=$ control $0.99 \pm$ $0.07(n=16)$, spared $1.50 \pm 0.12(n=13)$, deprived $0.98 \pm$ $0.12(n=11)$; PICK $1-/-=$ control $0.92 \pm 0.08(n=12)$, spared $1.36 \pm 0.09(n=19)$, deprived $0.98 \pm 0.07(n=15)]$. Therefore, although PICK1 - / - synapses were lacking in CPAMPARs, AMPAR-EPSCs were nevertheless potentiated by prior experience.

To exclude the possibility that changes in AMPA:NMDA ratio were due entirely to plasticity of NMDAR currents, we examined the amplitude of AMPAR-EPSCs resulting from quantal evoked glutamate release $\left(\mathrm{Sr}^{2+}-\mathrm{mEPSCs}\right)$ by replacing extracellular $\mathrm{Ca}^{2+}$ with $\mathrm{Sr}^{2+}(3 \mathrm{mM})$. Comparison of $\mathrm{Sr}^{2+}$-mEPSCs revealed that amplitudes were significantly increased by single-row expe- rience in both PICK $1+/+$ and PICK $1-/-$ mice (Fig. $3 A-C$ ) $\left[\mathrm{Sr}^{2+}\right.$-mEPSC amplitude: PICK $1+/+=$ control $8.67 \pm 0.29$ $(n=12)$, spared $11.84 \pm 0.50(n=10)$, deprived $9.65 \pm 0.29$ $(n=10) ;$ PICK $1-/-=$ control $9.03 \pm 0.22(n=8)$, spared $11.52 \pm 0.52(n=10)$, deprived $8.66 \pm 0.36(n=9)]$, suggesting that AMPAR plasticity formed the basis for an increase in AMPA: NMDA ratio. Consistent with PICK1-dependent insertion of CP-AMPARs, $\mathrm{Sr}^{2+}$-mEPSCs exhibited faster decay kinetics in spared neurons following single-row experience in PICK $1+/+$ but not in PICK $1-/-$ mice (Fig. $3 D-F$ ) $\left[\mathrm{Sr}^{2+}-\mathrm{mEPSC} \tau_{\text {decay }}\right.$ : PICK $1+/+=$ control $5.47 \pm 0.40(n=11)$, spared $3.77 \pm 0.27$ $(n=11)$, deprived $5.51 \pm 0.31(n=10)$; PICK $1-/-=$ control $6.46 \pm 0.56(n=8)$, spared $5.63 \pm 0.39(n=10)$, deprived $6.14 \pm$ $0.41(n=9)]$.

Examination of spontaneous mEPSCs from control mice revealed that amplitude, frequency, and decay kinetics of mEPSCs were unaffected by PICK1 genotype [PICK1+/+: mEPSC amplitude $=7.49 \pm 0.32 \mathrm{pA}(n=7), \operatorname{mEPSC} \tau_{\text {decay }}=5.26 \pm 0.27$ $\mathrm{ms}(n=7)$, mEPSC interevent interval $=170.2 \pm 18.6 \mathrm{~ms}$ $(n=6)$; PICK1-/-: mEPSC amplitude $=7.50 \pm 0.42 \mathrm{pA}$ $(n=7)$, mEPSC $\tau_{\text {decay }}=5.18 \pm 0.19 \mathrm{~ms}(n=7)$, mEPSC interevent interval $=152.4 \pm 9.9 \mathrm{~ms}(n=7)]$, indicating that PICK1 does not affect synaptic efficacy or synaptic AMPAR phenotype under basal conditions. Thus, while PICK1 promotes CARP, this phenomenon does not occur during normal sensory activity, and is not required for normal development of synaptic responses.

One mechanism by which PICK1 may lead to the appearance of CP-AMPARs at synapses is by altering the distribution of 
A

$\mathrm{PICK} 1+/+$

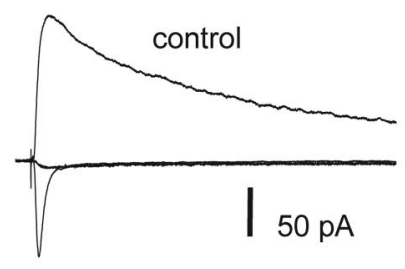

PICK1 -/-

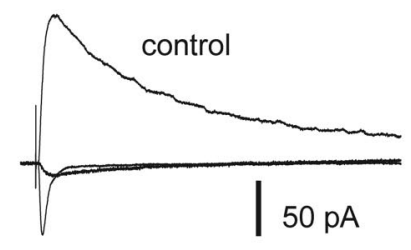

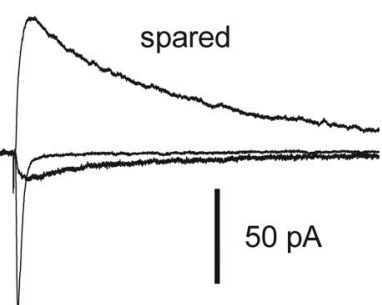

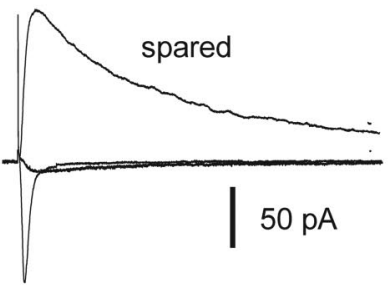

B
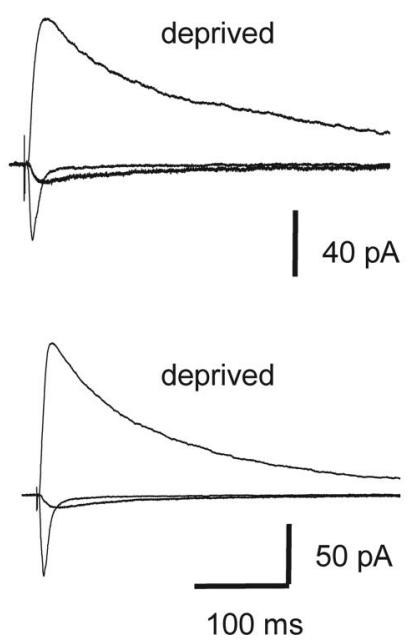

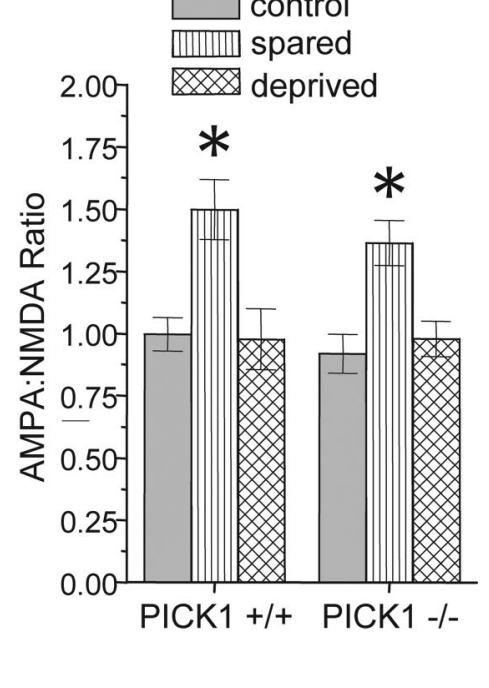

Figure 2. Sensory-driven enhancement of AMPA:NMDA ratio does not require PICK1. $A$, Overlay of EPSCs evoked at $-70,0$, and $+40 \mathrm{mV} . \boldsymbol{B}$, Mean AMPA:NMDA ratio for EPSCS. ${ }^{*} p<0.001$ by ANOVA followed by Bonferroni post hoc comparison.

A

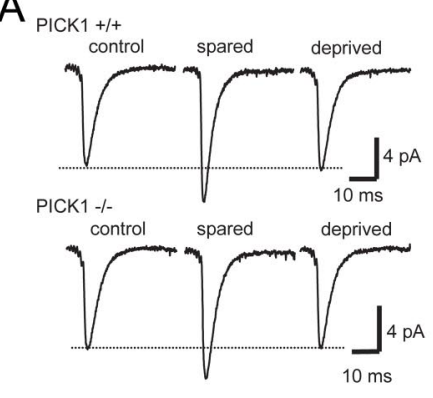

B

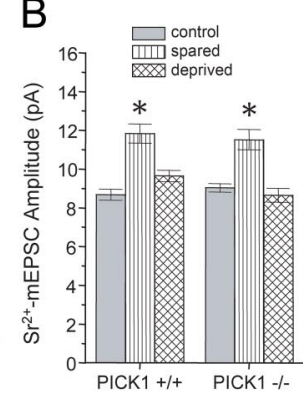

E

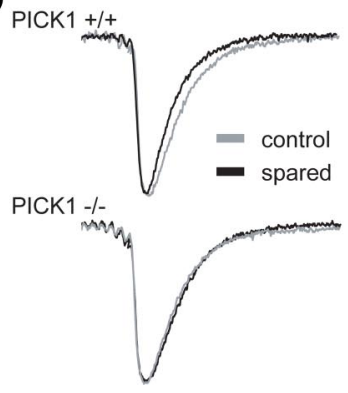

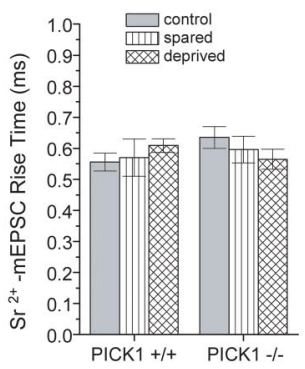

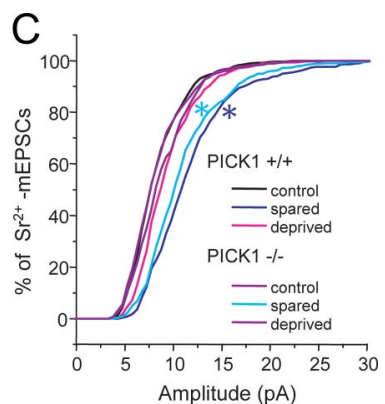

$\mathrm{F}$

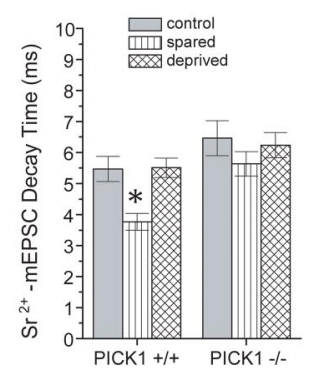

Figure 3. Quantal AMPAR-EPSCs are potentiated by single-row experience independent of PICK1 or CP-AMPARs. A, Mean AMPAR miniature EPSCs evoked by stimulation in the presence of $\mathrm{Sr}^{2+}\left(\mathrm{Sr}^{2+}-\mathrm{mEPSCS}\right)$ at layer $4-2 / 3$ inputs. $\boldsymbol{B}$, Mean amplitude of $\mathrm{Sr}^{2+}$-mEPSCs. C, Cumulative distribution of $\mathrm{Sr}^{2+}$-mEPSC amplitudes. D, Overlay of $\mathrm{Sr}^{2+}$-mEPSC, illustrating faster decay of AMPAR currents after single-row experience in spared barrel columns of PICK1 + / + but not PICK1 - / - mice. E, Mean rise time (20-80\%) of $\mathrm{Sr}^{2+}$-mEPSC s. $\boldsymbol{F}$, Mean $\tau_{\text {decay }}$ of $\mathrm{Sr}^{2+}$-mEPSC s. $\boldsymbol{B}, \boldsymbol{F},{ }^{*} p<0.01$ by ANOVA followed by Bonferroni post hoc comparison. $C$, ${ }^{*} p<0.0001$, Kolmogorov-Smirnov test comparing spared to control.

CP-AMPARs between intracellular and surface compartments. Therefore, to determine whether PICK1 affects the localization of AMPAR subtypes, we performed surface biotinylation of barrel cortex tissue. Since the vast majority of forebrain AMPARs likely consist of GluR1 or GluR2, alone or in combination (Wenthold et al., 1996; Lu et al., 2009), we focused our attention on these subunits. As predicted, PICK1 knock-outs showed higher surface/ total levels of GluR2 (Fig. $4 A, B)[124.7 \pm 6.1 \%$ of wild type $(n=$ 5 animals each)], indicating that PICK1 negatively regulates membrane expression of GluR2-containing AMPARs. Inter- estingly, PICK1 deletion also resulted in lower surface expression of GluR1 (Fig. $4 B)[78.8 \pm 6.9 \%$ of wild type $(n=4$ animals each)]. No significant differences in total AMPAR expression levels were observed (Fig. 4B) [PICK1-/-: GluR1 $110.6 \pm 7.0 \%$ of wild type $(n=4$ animals each); PICK1-/-: GluR2 $92.2 \pm 6.9 \%$ of wild type ( $n=5$ animals each)].

To directly examine whether PICK1 promotes the surface expression of $\mathrm{CP}$ AMPARs, we used immunodepletion of GluR2-containing AMPARs from cortical lysates (Fig. 4C) [as done by Wenthold et al. (1996) and Conrad et al. (2008)] to examine the fraction of GluR1 remaining. Following GluR2 depletion to $1.83 \pm$ $1.16 \%$ of input level in PICK1 knock-outs and $2.75 \pm 0.75 \%$ in wild-type littermates ( $n=7$ slices from 5 animals, each genotype), a substantial amount of total GluR1 remained (Fig. 4C). However, PICK1 genotype did not significantly affect the fraction of total unbound GluR1 (Fig. 4C) $(\mathrm{PICK} 1+/+=20.4 \pm 5.8 \%$, PICK $1-/-$ $=15.5 \pm 4.6 \%)$, suggesting that the total level of CP-AMPARs was similar in PICK1 knock-outs. In contrast, the fraction of surface biotinylated GluR1 that remained was significantly lower in PICK1 knock-outs (Fig. 4E) (surface unbound GluR1: PICK $1+/+=4.23 \pm 0.4 \%$, PICK $1-/-=2.63 \pm 0.4 \%)$. This could not be explained by uneven depletion of GluR2 from PICK1 - / - lysates, since surface unbound GluR2 did not differ from wild-type littermates (Fig. 4D) (surface unbound GluR2: PICK $1+/+=0.42 \pm 0.2 \%$, PICK $1-/-=0.41 \pm 0.1 \%)$. Importantly, because our whole-cell recordings do not indicate the presence of CP-AMPARs at synapses under basal conditions, these data suggest that PICK1 facilitates the surface expression of CP-AMPARs at extrasynaptic sites. 


\section{Discussion}

Despite significant evidence linking CPAMPARs to increased neurotransmission, the regulation of CARP and its relationship to response potentiation remains to be established. In agreement with a previous report in which sensory experience resulted in the enhancement of CP-AMPAR currents (Clem and Barth, 2006), we show that sensory-induced strengthening of cortical synapses is accompanied by the appearance of synaptic CP-AMPARs. CARP required PICK1, since PICK1 knockout mice did not undergo experiencedependent changes in EPSC rectification or quantal EPSC kinetics. However, the lack of CP-AMPARs at synaptic sites had no impact on the transmission efficacy, since AMPAR-EPSC amplitudes after singlerow experience were unaffected by PICK1 deletion.

In agreement with previous reports that C-terminal GluR2 interactions facilitate the synaptic expression of GluR2lacking AMPARs (Liu and Zukin, 2007), the present data demonstrate that the GluR2-binding protein PICK1 plays an important role in CARP. Our observation of increased surface GluR2 in PICK1 knock-outs complements a reported PDZdomain-dependent decrease in surface GluR2 induced by PICK1 overexpression (Terashima et al., 2004), and suggests that PICK1 may function to internalize or retain GluR2-containing AMPARs within intracellular stores. Consistent with the latter possibility, PICK1 knock-out hippocampal neurons exhibit accelerated recycling of GluR2 to the surface after NMDA-induced internalization (Lin and Huganir, 2007). A decrease in GluR1 surface levels could represent a compensatory downregulation of GluR2lacking AMPARs, or could indicate a novel role for PICK1 in GluR1 trafficking despite the lack of any known direct interaction between these proteins. Importantly, a portion of the surface GluR1 deficit was accounted for by lower surface levels of GluR1-containing/ GluR2-lacking AMPARs. Since the extrasynaptic dendritic surface supplies AMPARs to synaptic sites for constitutive recycling and synaptic strengthening (Shepherd and Huganir, 2007), this compartment may be the source of receptors that contribute to CARP. While our data do not address the potential role of experience-dependent AMPAR synthesis (Conrad et al., 2008), PICK1 likely facilitates the surface and/or synaptic expression of any new CP-AMPARs, since these do not appear to contribute to transmission in PICK1 knock-outs.

Our data argue that PICK1 is not critical for cortical synaptic strengthening during sensory experience. This result is in contrast with a recent report in which PICK1 knock-outs exhibited reduced LTP in the hippocampal CA1 area (Terashima et al., 2008). In this system, a transient potentiation that was mediated by CPAMPARs occurred in the absence of PICK1, seemingly ruling out the unavailability of CP-AMPARs as an explanation for LTP failure. Peptide interference with PICK1-GluR2 binding has varying effects on EPSC amplitudes in different systems, including a slow
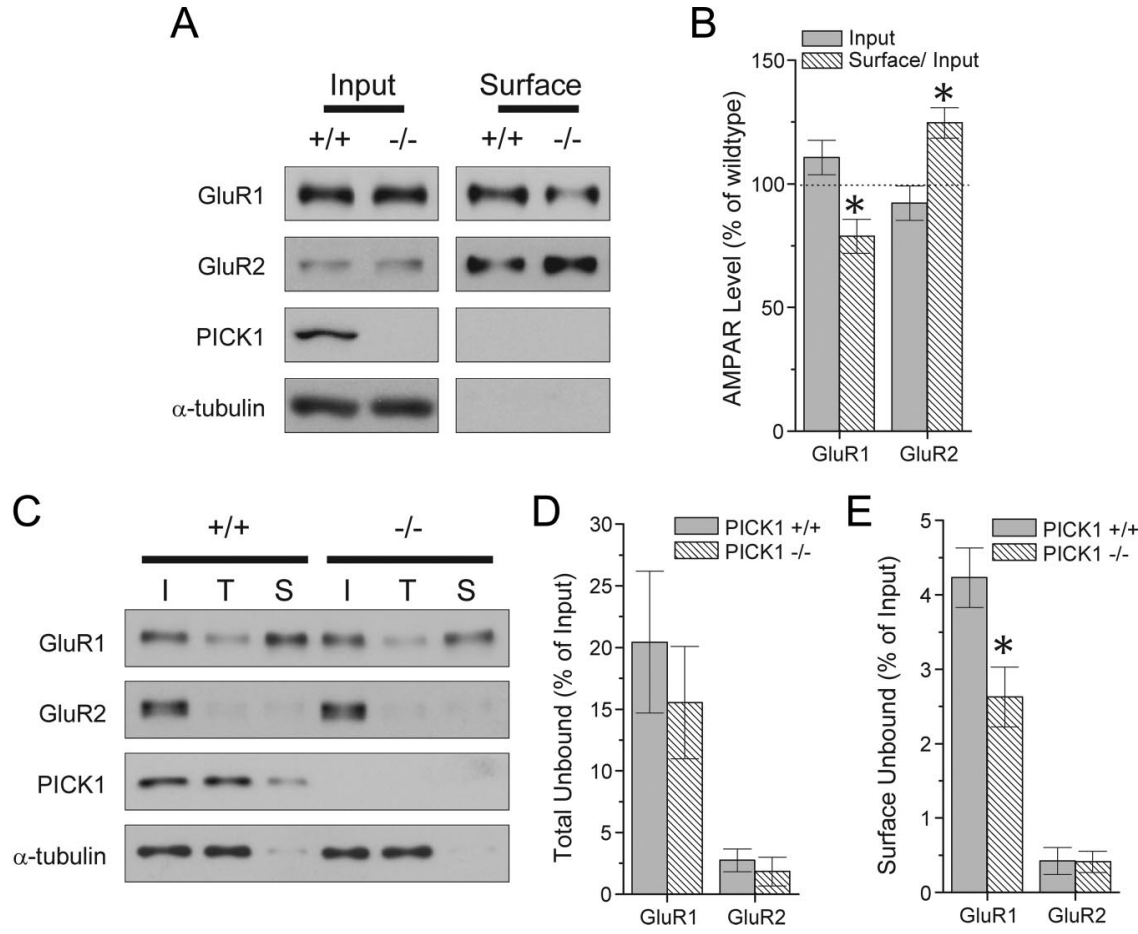

Figure 4. PICK1 facilitates the surface expression of GluR2-lacking AMPARs. A, Example experiment in which acute barrel cortex slices from PICK1 - / - mice and their PICK1 + / littermates were subjected to surface biotinylation assay. The relative level of surface and total AMPARs was assessed by Western blot using specific antibodies against GluR1 and GluR2 subunits after firs

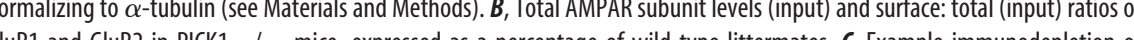
fo enable subsequent affinity purification of surface AMPARs. I, Input; $T$, total unbound fraction; $S$, surface unbound ing two rounds of GluR2 immunodepletion. Surface unbound fraction was loaded at $30 \times$ input concentration. $D, E_{1}$ Methods). ${ }^{*} p<0.05$, Student's two-tailed $t$ test comparing PICK1 $+/+$ and PICK $1-/-$ mice.

run-up in CA1 pyramids and cerebellar stellate cells (Kim et al., 2001; Gardner et al., 2005; Yao et al., 2008), a run-down in CA3 pyramids (Ho et al., 2007), and no effect in cerebellar Purkinje cells (Xia et al., 2000). Together with our data, these findings imply that PICK1 regulation of synaptic strength exhibits regionand cell-type-specific differences. Moreover, we do not exclude the possibility that PICK1 is required for layer $4 \rightarrow 2 / 3$ synaptic strengthening under different stimulus contingencies, or after development of this system is complete.

A well known feature of CP-AMPARs is their greatly enhanced single-channel conductance compared to AMPARs that contain GluR2 (Swanson et al., 1997). The subject of AMPAR conductance has been of considerable interest since early studies reported increases in single-channel conductance estimated from hippocampal EPSCs following LTP (Benke et al., 1998) or wholecell infusion of active CaMKII (Derkach et al., 1999). Other reports have shown that subunit composition, and specifically the inclusion of the edited form of GluR2, severely restricts the ion conductance of AMPARs (Swanson et al., 1997; Oh and Derkach, 2005). Given the reduced availability of high-conductance receptors, it is therefore surprising that AMPAR-EPSC amplitudes were increased in PICK1 knock-outs during sensory experience to levels commensurate with wild-type mice. Synaptic strength thus appears to be augmented in PICK1 knock-outs by an increased density of low-conductance GluR2-containing receptors. It might be argued that GluR2-lacking AMPARs could be required for strengthening only a subset of inputs, such as those 
that were previously AMPA-silent. However, we are able to reject this mechanism as a major contribution to plasticity since any change in the number of silent synapses in PICK1 knock-outs would have been reflected in the AMPA:NMDA ratio.

Much consideration has been given to the role played by subunit composition in the AMPAR trafficking events mediating synaptic strengthening (Malinow and Malenka, 2002). In the present study, layer $4-2 / 3$ synapses existed as either GluR2-rich (PICK1-/-) or GluR2-deficient $(\mathrm{PICK} 1+/+$ ) following sensory experience, despite equivalent strength of transmission. CP-AMPARs can be expressed at synapses for many hours to days following acute and chronic stimuli. This reconfiguration may support signaling cascades coupled to $\mathrm{Ca}^{2+}$ influx through CP-AMPARs (Gu et al., 1996; Mahanty and Sah, 1998; Liu and Cull-Candy, 2000; Asrar et al., 2009), which might influence the long-term consolidation of synaptic plasticity. Alternatively, CP-AMPARs might endow recently modified synapses with altered sensitivity to further activity, such that subsequent LTP or LTD is enhanced (Jia et al., 1996, Ho et al., 2007). Such metaplasticity may serve the purpose of allowing these inputs to undergo modification before the consolidation of synaptic strengthening.

The present data implicate PICK1 in the control of AMPAR subunit composition during an important developmental phase of barrel cortex. Specifically, we find that PICK1 promotes the synaptic incorporation of CP-AMPARs during partial whisker deprivation, a paradigm associated with enhancement of whiskerevoked spiking activity in the intact animal (Glazewski et al., 2007; Benedetti et al., 2009). Contrary to the expected impact of a loss of high-conductance CP-AMPARs at synapses, we found that sensory-induced increases in AMPAR currents were not affected by PICK1 deletion. These results point to the existence of a mechanism for incorporating CP-AMPARs that can operate independently from sensory-evoked potentiation, and that may function together with previously described physiological changes in metaplasticity of strengthened synapses (Clem et al., 2008).

\section{References}

Asrar S, Zhou Z, Ren W, Jia Z (2009) $\mathrm{Ca}(2+)$ permeable AMPA receptor induced long-term potentiation requires PI3/MAP kinases but not $\mathrm{Ca} /$ CaM-dependent kinase II. PLoS One 4:e4339.

Bell JD, Park E, Ai J, Baker AJ (2009) PICK1-mediated GluR2 endocytosis contributes to cellular injury after neuronal trauma. Cell Death Differ 16:1665-1680.

Bellone C, Lüscher C (2006) Cocaine triggered AMPA receptor redistribution is reversed in vivo by mGluR-dependent long-term depression. Nat Neurosci 9:636-641.

Benedetti BL, Glazewski S, Barth AL (2009) Reliable and precise neuronal firing during sensory plasticity in superficial layers of primary somatosensory cortex. J Neurosci 29:11817-11827.

Benke TA, Lüthi A, Isaac JT, Collingridge GL (1998) Modulation of AMPA receptor unitary conductance by synaptic activity. Nature 393:793-797.

Cheetham CE, Hammond MS, Edwards CE, Finnerty GT (2007) Sensory experience alters cortical connectivity and synaptic function site specifically. J Neurosci 27:3456-3465.

Clem RL, Barth A (2006) Pathway-specific trafficking of native AMPARs by in vivo experience. Neuron 49:663-670.

Clem RL, Celikel T, Barth AL (2008) Ongoing in vivo experience triggers synaptic metaplasticity in the neocortex. Science 319:101-104.

Conrad KL, Tseng KY, Uejima JL, Reimers JM, Heng LJ, Shaham Y, Marinelli M, Wolf ME (2008) Formation of accumbens GluR2-lacking AMPA receptors mediates incubation of cocaine craving. Nature 454:118-121.

Derkach V, Barria A, Soderling TR (1999) Ca2+/calmodulin-kinase II enhances channel conductance of alpha-amino-3-hydroxy-5-methyl-4isoxazolepropionate type glutamate receptors. Proc Natl Acad Sci U S A 96:3269-3274.
Dixon RM, Mellor JR, Hanley JG (2009) PICK1-mediated glutamate receptor subunit 2 (GluR2) trafficking contributes to cell death in oxygen/ glucose-deprived hippocampal neurons. J Biol Chem 284:14230-14235.

Feldman DE, Brecht M (2005) Map plasticity in somatosensory cortex. Science 310:810-815.

Finnerty GT, Roberts LS, Connors BW (1999) Sensory experience modifies the short-term dynamics of neocortical synapses. Nature 400:367-371.

Gardner SM, Takamiya K, Xia J, Suh JG, Johnson R, Yu S, Huganir RL (2005) Calcium-permeable AMPA receptor plasticity is mediated by subunitspecific interactions with PICK1 and NSF. Neuron 45:903-915.

Glazewski S, Fox K (1996) Time course of experience-dependent synaptic potentiation and depression in barrel cortex of adolescent rats. J Neurophysiol 75:1714-1729.

Glazewski S, Benedetti BL, Barth AL (2007) Ipsilateral whiskers suppress experience-dependent plasticity in the barrel cortex. J Neurosci 27: $3910-3920$.

Goel A, Jiang B, Xu LW, Song L, Kirkwood A, Lee HK (2006) Cross-modal regulation of synaptic AMPA receptors in primary sensory cortices by visual experience. Nat Neurosci 9:1001-1003.

Gu JG, Albuquerque C, Lee CJ, MacDermott AB (1996) Synaptic strengthening through activation of $\mathrm{Ca} 2+-$ permeable AMPA receptors. Nature 381:793-796.

Ho MT, Pelkey KA, Topolnik L, Petralia RS, Takamiya K, Xia J, Huganir RL, Lacaille JC, McBain CJ (2007) Developmental expression of $\mathrm{Ca}^{2+}$ permeable AMPA receptors underlies depolarization-induced long-term depression at mossy fiber CA3 pyramid synapses. J Neurosci 27:11651-11662.

Jia Z, Agopyan N, Miu P, Xiong Z, Henderson J, Gerlai R, Taverna FA, Velumian A, MacDonald J, Carlen P, Abramow-Newerly W, Roder J (1996) Enhanced LTP in mice deficient in the AMPA receptor GluR2. Neuron 17:945-956.

Kim CH, Chung HJ, Lee HK, Huganir RL (2001) Interaction of the AMPA receptor subunit GluR2/3 with PDZ domains regulates hippocampal long-term depression. Proc Natl Acad Sci U S A 98:11725-11730.

Lin DT, Huganir RL (2007) PICK1 and phosphorylation of the glutamate receptor 2 (GluR2) AMPA receptor subunit regulates GluR2 recycling after NMDA receptor-induced internalization. J Neurosci 27:1390313908.

Liu B, Liao M, Mielke JG, Ning K, Chen Y, Li L, El-Hayek YH, Gomez E, Zukin RS, Fehlings MG, Wan Q (2006) Ischemic insults direct glutamate receptor subunit 2-lacking AMPA receptors to synaptic sites. J Neurosci 26:5309-5319.

Liu SJ, Cull-Candy SG (2005) Subunit interaction with PICK and GRIP controls $\mathrm{Ca} 2+$ permeability of AMPARs at cerebellar synapses. Nat Neurosci 8:768-775.

Liu SJ, Zukin RS (2007) Ca2+-permeable AMPA receptors in synaptic plasticity and neuronal death. Trends Neurosci 30:126-134.

Liu SQ, Cull-Candy SG (2000) Synaptic activity at calcium-permeable AMPA receptors induces a switch in receptor subtype. Nature 405:454-458.

Lu W, Shi Y, Jackson AC, Bjorgan K, During MJ, Sprengel R, Seeburg PH, Nicoll RA (2009) Subunit composition of synaptic AMPA receptors revealed by a single-cell genetic approach. Neuron 62:254-268.

Mahanty NK, Sah P (1998) Calcium-permeable AMPA receptors mediate long-term potentiation in interneurons in the amygdala. Nature 394: 683-687.

Malinow R, Malenka RC (2002) AMPA receptor trafficking and synaptic plasticity. Annu Rev Neurosci 25:103-126.

Noh KM, Yokota H, Mashiko T, Castillo PE, Zukin RS, Bennett MV (2005) Blockade of calcium-permeable AMPA receptors protects hippocampal neurons against global ischemia-induced death. Proc Natl Acad Sci U S A 102:12230-12235.

Oh MC, Derkach VA (2005) Dominant role of the GluR2 subunit in regulation of AMPA receptors by CaMKII. Nat Neurosci 8:853-854.

Park JS, Voitenko N, Petralia RS, Guan X, Xu JT, Steinberg JP, Takamiya K, Sotnik A, Kopach O, Huganir RL, Tao YX (2009) Persistent inflammation induces GluR2 internalization via NMDA receptor-triggered PKC activation in dorsal horn neurons. J Neurosci 29:3206-3219.

Prince HK, Conn PJ, Blackstone CD, Huganir RL, Levey AI (1995) Downregulation of AMPA receptor subunit GluR2 in amygdaloid kindling. J Neurochem 64:462-465.

Shepherd JD, Huganir RL (2007) The cell biology of synaptic plasticity: AMPA receptor trafficking. Annu Rev Cell Dev Biol 23:613-643. 
Steinberg JP, Takamiya K, Shen Y, Xia J, Rubio ME, Yu S, Jin W, Thomas GM, Linden DJ, Huganir RL (2006) Targeted in vivo mutations of the AMPA receptor subunit GluR2 and its interacting protein PICK1 eliminate cerebellar long-term depression. Neuron 49:845-860.

Swanson GT, Kamboj SK, Cull-Candy SG (1997) Single-channel properties of recombinant AMPA receptors depend on RNA editing, splice variation, and subunit composition. J Neurosci 17:58-69.

Tempia F, Kano M, Schneggenburger R, Schirra C, Garaschuk O, Plant T, Konnerth A (1996) Fractional calcium current through neuronal AMPA-receptor channels with a low calcium permeability. J Neurosci 16:456-466.

Terashima A, Cotton L, Dev KK, Meyer G, Zaman S, Duprat F, Henley JM, Collingridge GL, Isaac JT (2004) Regulation of synaptic strength and AMPA receptor subunit composition by PICK1. J Neurosci 24:5381-5390.

Terashima A, Pelkey KA, Rah JC, Suh YH, Roche KW, Collingridge GL,
McBain CJ, Isaac JT (2008) An essential role for PICK1 in NMDA receptordependent bidirectional synaptic plasticity. Neuron 57:872-882.

Wenthold RJ, Petralia RS, Blahos J II, Niedzielski AS (1996) Evidence for multiple AMPA receptor complexes in hippocampal CA1/CA2 neurons. J Neurosci 16:1982-1989.

Xia J, Zhang X, Staudinger J, Huganir RL (1999) Clustering of AMPA receptors by the synaptic PDZ domain-containing protein PICK1. Neuron 22:179-187.

Xia J, Chung HJ, Wihler C, Huganir RL, Linden DJ (2000) Cerebellar longterm depression requires PKC-regulated interactions between GluR2/3 and PDZ domain-containing proteins. Neuron 28:499-510.

Yao Y, Kelly MT, Sajikumar S, Serrano P, Tian D, Bergold PJ, Frey JU, Sacktor TC (2008) PKM zeta maintains latelong-term potentiation by $N$-ethylmaleimidesensitive factor/GluR2-dependent trafficking of postsynaptic AMPA receptors. J Neurosci 28:7820-7827. 